\title{
4 \\ COMPLIANCE-AS-A-SERVICE IN INFORMATION TECHNOLOGY MANUFACTURING ORGANIZATIONS: An Exploratory Case Study
}

\author{
Tom Butler \\ Bill Emerson \\ College of Business and Law \\ University College Cork \\ Cork, Republic of Ireland \\ Damien McGovern \\ Compliance \& Risks \\ Cork, Republic of Ireland \\ Cork, Ireland
}

\begin{abstract}
In recent years, environmental concerns have led to a significant increase in the number and scope of compliance imperatives across all global regulatory environments. The complexity and geographical diversity of these environments has caused considerable problems for organizations, particularly those in high-technology industries. This paper first employs institutional theory to help understand the challenges for information technology manufacturing organizations that emanate from global institutional environments. While cultural-cognitive and normative influences from society-at-large and industry-based bodies have stimulated environment-oriented corporate social responsibility initiatives, it is undoubtedly regulatory influences that have generated the deepest responses in terms of the adoption of new complianceoriented procedures and protocols. This paper first describes the general response from the organizational field in which high-technology firms operate and notes the extent of the response, with environmental compliance management systems being one of the institutional arrangements that organizations have adopted. The findings of empirical research based on
\end{abstract}

Please use the following format when citing this chapter:

Butler, T., Emerson, B., and McGovern, D., 2008, in IFIP International Federation for Information Processing, Volume 267, Information Technology in the Service Economy: Challenges and Possibilities for the $21^{\text {st }}$ Century, eds. Barrett, M., Davidson, E., Middleton, C., and DeGross, J. (Boston: Springer), pp. 43-59. 
Compliance \& Risks Ltd.'s compliance-to-product application and its deployment in Napa Inc., a Silicon Valley-based Fortune 500 company, are then offered and analyzed to illustrate the scale and scope of information systems support required to institute adequate compliance-oriented protocols and procedures in response to global regulatory influences, while also answering concerns raised by normative and cultural-cognitive sources.

Keywords Institutional theory, compliance, knowledge management, environmental compliance management systems

\section{INTRODUCTION}

Compliance with regulatory requirements of one sort of another has been with business enterprises for some time (Taylor 2005). In recent times, however, environmental concerns have led to a growing emphasis on compliance issues surrounding issues of energy consumption by, and the use of hazardous substances in, products across all industry sectors (Hristev 2006; Kellow 2002). The influence of environmentally oriented regulatory and social pressures are especially evident in the information technology sector (Murugesan 2007), particularly as shorter product life cycles, and longer product lines, have increased the use of materials that are deemed hazardous to the environment and, ultimately, to human health (Avila 2006; Brown 2006). Companies like Dell (2007) and Hewlett Packard (2006), for examples, increasingly advertise how they are exercising corporate social responsibility with respect to "green" pressures-both regulatory and social in origin.

Scott (2004) maintains that institutional theory has as its concern the forces that shape social structures, schemas, rules, norms, and routines and which, in turn, affect the behavior of social actors. It is clear from $\operatorname{Scott}(2001,2004)$ that regulatory, normative and cultural-cognitive institutional influences shape organizational processes and structures, and help define what is effective performance or efficient operation in organizations (Powell 1991). Thus, institutional theory provides a suitable conceptual lens with which to examine the impact of institutional forces generated by environmental concerns in the organizational field, population, and environment in which high-technology manufacturing firms compete (Chiasson and Davidson 2005). This study, therefore, adopts institutional theory to first explore and understand the regulatory, normative, and cultural-cognitive forces shaping the environmental compliance imperatives confronting IT manufacturing organizations. It also illustrates that IT manufacturing organizations have responded to institutional pressures by deploying information systems to support internal compliance processes - with, it is argued, limited success (Avila 2006; Brown 2006). This paper focuses on how one software application and data services vendor, Compliance \& Risks Ltd., had its compliance knowledge management system adopted by Napa Inc., a Fortune 500 high-tech manufacturer, in order to address the considerable challenge of global product compliance through IT-supported compliance-oriented protocols and procedures.

The research objective of this study is to explore how global environmental regulations have shaped the organization-level responses of firms in the IT manufacturing sector and to investigate how IT and data services are being employed to support new 
organizational protocols and procedures to address the challenges posed by green legislation.

\section{APPLYING INSTITUTIONAL THEORY TO UNDER- STAND COMPLIANCE IMPERATIVES FACING ORGANIZATIONS}

Institutions are "the humanly devised constraints that structure political, economic, and social interactions. They consist of both informal constraints (sanctions, taboos, customs, traditions, and codes of conduct), and formal rules (constitutions, laws, property rights)" (North 1991, p. 97). According to DiMaggio and Powell (1983, p. 143), an organizational field is comprised of "Those organizations that, in the aggregate, constitute a recognized area of institutional life: [it consists of] key suppliers, resource and product consumers, regulatory agencies, and other organizations that produce similar services or products." An organizational field is characterized by coercive (regulative and legislative) influences from government departments, state-sponsored agencies, the judiciary, and so on, in addition to normative and mimetic (cultural-cognitive; Scott 2001) influences from related organizations (suppliers, consulting organizations, distributors, professional bodies, etc.), competitors, stakeholders (nongovernment organizations, analysts, investment funds, for examples) and other related social entities. It is clear from DiMaggio and Powell, as with Scott (2001), that the external agencies which constitute an organizational field exert a significant influence over an organization's structures, policies, practices, and procedures. Following Chiasson and Davidson (2005), this study conceptualizes the organizational field as the electrical and electronics industry (although all organizations are now affected by environmental regulations of one kind or another) and the organizational population/environment as the high-tech IT manufacturing sector. However, we argue that, as recent regulatory developments in the European Union have illustrated, organizational fields exist within a global/societal environment rather than national environments.

\subsection{Regulative or Coercive Influences on IT Manufacturing Organizations}

Drawing on Scott (2001), the emphasis of regulatory institutional influences is on coercion, indicators of which are rules and laws, which agents such as governments and regulatory agencies legitimize using legal sanctions to ensure compliance. Institutional carriers, on the other hand, are social structures such as governance and power systems, which institute rules and laws, the organizational response to which is to institutionalize routines such as protocols and procedures. This section, therefore, focuses on governance power systems, rules, and laws that shape corresponding organizational complianceoriented procedures and protocols.

High-tech IT manufacturing organizations operate in highly complex regulatory institutional environments internationally and, consequently, face a bewildering range of diverse regulations (Avila 2006; Hristev 2006). For example, recent European Union 
regulations such as the Restriction of Hazardous Substances Directive (RoHS), the Waste Electrical and Electronic Equipment Directive (WEEE), and the Registration, Evaluation and Authorisation of Chemicals (REACh) Regulation have enormous implications for diverse industry sectors operating globally (European Commission 2006; Hristev 2006). The implementation of the WEEE and RoHS directives resulted in highly complex legislation in EU member states, which does not lend itself to easy comprehension, application, and integration into an organization's research, development, manufacturing, and logistics processes (Pecht 2004). However, the task of maintaining compliance will become even more onerous for the IT manufacturing industry and related sectors, not only because of the recent moves to include 46 new hazardous substances on top of the original six under EU RoHS, but as the new REACh regulation came into force in June 2007. This new law requires organizations to specify the possible dangers of combinations of chemicals present in their products not only on disposal, but also while in use (Bush 2007). It will also place new disclosure requirements on companies under Article 33 by ensuring that customers, and also interested NGOs like Greenpeace, can insist on disclosure on a black list of substances. While the EU's environmental laws have received much attention, others are no less stringent. The Environmental Protection Agency (EPA) in the United States has issued a raft of legislation covering all hazardous substances across the whole range of manufacturing sectors, while Japan also has highly demanding laws (Hristev 2006). Over the last two years, Korea, Australia, Canada, and U.S. states such as California have introduced legislation similar to the RoHS and WEEE directives, while in China, a similar directive known as the China RoHS, or the Methods for the Control of Pollution by Electronic Information Products Directive, came into force in March 2007. The need to address compliance legislation in different geographical locations adds complexity for global IT manufacturing organizations; however, determining the applicable regulation for a given geographical area can be complicated by the problem of understanding which products are covered by, or are exempt from, sets of seemingly conflicting regulations (Kellow 2002).

The European Commission estimates that the cost of being in compliance with its new REACh legislation will be upwards of $€ 5.2$ billion ( $\$ 7$ billion) (European Commission 2006). Independent research also reports that the cost of compliance with RoHS and WEEE is approximately 2 to 3 percent of the cost of goods sold, a not insignificant amount given the size of the IT sector (Spiegel 2005). However, while the costs of ensuring compliance are considerable, the costs of not being in compliance are even more significant, with companies facing the risk of exclusion from key markets, stopped shipments, and product recalls, with a corresponding loss of revenue, and potentially disastrous consequences for brand image and/or corporate reputation (Avila 2006, Brown 2006; Goosey 2007). In cases of a serious breach of compliance, firms may also be faced with hefty fines and/or criminal prosecution (Brown 2006).

\subsection{Normative and Cultural-Cognitive Influences on Environmental Compliance}

While the forgoing illustrates the relatively strong incentives to comply with regulative imperatives, normative and cultural-cognitive influences increasingly come into play. Industry standards and professional bodies such as IEE and IEEE, customers, 
and suppliers are the agents bringing normative influences into play, while nongovernment organizations and other social stakeholders bring cultural-cognitive influences to bear (see Eisner 2004). In terms of the former type of influence, manufacturer associations, original equipment manufacturers, and firms that source components from suppliers in the industry mandate compliance to the regulations and standards in the institutional environments they face (Avila 2006; Pecht 2004). Take, for example, Eisner's (2004) report on the Ford Motor Company's decision to have all of its suppliers be ISO14001 compliant, thus forcing environmental social responsibility down the supply chain. In contrast, one recent example of cultural-cognitive influences comes from the nongovernment organization Greenpeace, which tests IT and electronic appliances for the presence of hazardous substances; Greenpeace publishes the results of its tests on the Internet in order to influence environmentally conscious customers and investors (Greenemeier 2007). It is clear, however, from recent practitioner analyses by the Aberdeen Group (Brown 2006) and McLean and Rasmussen (2007), that normative and cultural-cognitive influences aimed at generating corporate social responsibility are less influential in shaping organizational responses to environmental issues than regulatory influences, as it is hoped by organizations that addressing the latter will help address normative and cultural-cognitive influences as well.

\subsection{Information Systems Support for Regulatory Compliance}

Avila (2006) argues that information systems are required to help address the challenge facing the IT manufacturing industry in responding to the increasingly complex global regulatory environment. In terms of the organizational response of instituting suitable compliance-oriented protocols and standard procedures, Avila argues that, to be effective, information systems must, at base, possess material compliance analysis capabilities, the ability to reduce the total cost of compliance, and also to account for rapidly changing environmental regulations across multiple markets and geographies. However, in its recent study, The Aberdeen Group revealed that 80 percent of companies lacked a cohesive systems infrastructure to track, audit or manage product compliance. Most companies were relying on a variety of solutions that were not properly integrated, and which did not provide the necessary information needed to meet environmental regulations (Brown 2006).

Previous efforts to tackle corporate environmental auditing and reporting involved the implementation of environmental management systems (EMS) - which may, or may not, have been supported by IT (Eisner 2004). Eisner reports that EMS were an extension of total quality management, which helped companies define their corporate environmental policies and employed information on regulatory requirements and environmental impacts to determine quantifiable objectives and programs. It was only recently, however, that robust IT support for EMS emerged in the form of software-as-a-service tools that help companies manage environmental, health, and safety compliance; DuPont, Chevron, and Johnson \& Johnson are three large multinational organizations using such systems (Brodkin 2007). While EMS grew out of the need to manage reasonably wellarticulated regulatory requirements, and to help companies address corporate social responsibility, they did not address the information asymmetry problems that emerged with more complex, stringent, and highly differentiated global regulatory compliance 
imperatives - hence, the emergence of environmental compliance management systems (ECMS).

A brief industry analysis conducted by the authors of the various high-profile ECMS offerings currently available from vendors such as SAP AG, TechniData AG, E2open, and Synapsis Technology revealed that they can be deployed as

- $\quad$ stand-alone applications (off-the-shelf packages that are configured or customized)

- hosted solutions (e.g., compliance-as-a-service)

- $\quad$ either of the above, integrated with existing product lifecycle management (PLM) or enterprise resource planning (ERP) systems

It is significant that the features of these application only meet, in part, the criteria proposed by Avila (2006) and outlined above. Our analysis also revealed that such ECMSs emerged from extant vendors' PLM systems (e.g., EMARS from Synapsis Technology, Inc., and Product Governance and Compliance from Agile Inc.), enterprise resource planning (ERP) systems (e.g., CfP from SAP AG and TechniData AG), or supply chain management (SCM) systems (e.g., E2open Inc.'s Eco-Compliance solution). A recent report by the Forrester Group (McLean and Rasmussen 2007) on the adoption of governance risk and compliance (GRC) applications (of which ECMS would be a subset) by organizations across all sectors failed to register any of those mentioned above - indeed McLean and Rasmussen concluded that the absence of both SAP AG and Oracle Corp. from their analysis indicated that they were not servicing the compliance needs of organizations. Extensive (unpublished) market research of over 50 global organizations by one of the authors between 2006 and 2007 revealed that Fortune 500 organizations admitted to using a variety of internal solutions based on, for example, Excel spreadsheets, basic database systems, and point solutions from a range of vendors (see Brown 2006). The GRC executives interviewed indicated that none of these solutions in use supported the organizational protocols and routines needed to manage regulatory environmental compliance on a global basis. It was found that they were particularly poor in addressing information asymmetry and knowledge sharing problems between regulators and companies (and vice versa), between companies and their stakeholders, and between various organizational functions.

\section{PARTICIPATORY RESEARCH ON COMPLIANCE-AS-A SERVICE}

An exploratory, instrumental case study design was chosen for this two year longitudinal study (Stake 1995; Yin 2003), which is the result of an ongoing, participative study by the university researchers with Compliance \& Risks Ltd. (C\&R) on the compliance-to-product (C2P) application. It must be noted that the research study, which commenced in August 2005, did not meet the criteria demanded of action research (Baskerville 1999); however, in an effort to capitalize on the synergy between the university researchers knowledge of KM theory and IS design and C\&R practitioners' "situated, practical theory" (Baskerville 1999, p. 17), a case-based participatory research strategy was chosen as the most appropriate approach. 
Two university researchers participated in this study. Four practitioners from the company played an active role as coresearchers: the primary coresearcher was the founder of Compliance \& Risks Ltd., while the secondary coresearchers included the California-based software team's project manager and the chief design architect of the $\mathrm{C} 2 \mathrm{P}$, a senior software engineer from C\&R and the company's marketing and sales director. The majority (seven) of the development team were headquartered in northern California, with two being based in Europe. The company's legal data team and industry partners were primarily European based; however, it did have a number of lawyers working out of U.S. offices. The remaining participants included users of the pilot version of C2P at Napa Inc.

The data for the present study was gathered using semi-structured interviews during numerous meetings and on-site visits in Europe and the United States, spanning the period from August 2005 to April 2007; participant observation was also employed throughout (Yin 2003). It must be noted, however, that researchers had no access, at any time, to confidential client data, in accordance with C\&R's nondisclosure and confidentiality obligations to its clients. Internet-based teleconferencing technologies were also employed to facilitate meetings, in addition to e-mails and instant messaging. The data was interpreted and analyzed on an ongoing basis and augmented by official company documentation, including C\&R's business plan, training manuals, technology architecture documentation, and so on.

\section{COMPLIANCE-AS-A-SERVICE: FROM CONCEPT TO SERVICE-ORIENTED ARCHITECTURE}

The background to the emergence of the compliance-to-product application has its origins in C\&R's CEO's experience in regulatory intelligence for Deloitte in Brussels. This provided him with a unique perspective on the need for, and potential of, ECMS, or compliance knowledge management systems (CKMS) as he conceptualized them, especially in industry sectors affected by environmental regulations being introduced by the European Union. He identified the electrical and electronics industries, and in particular the IT sector, as a potential niche market for his new business method and CKMS innovation. In order to help translate his innovative idea, he developed a conceptual model of the components and processes of an enterprise-wide CKMS. As a legal expert, he identified what he termed a consumption problem, in that an information asymmetry existed between regulatory institutions and agencies and the companies covered by the environmental legislation they produced. In terms of institutional theory, if companies did not know of, or understand, environmental regulatory compliance imperatives with respect to products/materials and substances of interest, how could they institute appropriate organizational responses in the forms of protocols and procedures to ensure compliance? Information-related problems were not, however, confined to the consumption of legislation, as high-tech manufacturers source an enormous range of subassemblies, components, etc. from diverse suppliers arranged in multitiered, geographically dispersed, supply chains. Knowing what is in a given product or model, and if it is (or will be) in compliance with global regulatory instruments, therefore, adds to the difficulty in arriving at suitably designed and effective protocols and procedures. The 
following section describes the conceptual model that emerged in $C \& R$ in response to regulatory institutional pressures identified by its founder and other legal experts.

\subsection{The Compliance-to-Product Conceptual Model}

Practitioners at C\&R view CKMS for product compliance as being based on an integrative IT artefact that manages three high-level enterprise compliance processes viz. an external regulatory requirements gathering process, a compliance management process, and a knowledge management process (a fourth, the supply chain compliance process, was recently identified, but requires further elaboration). These processes concern themselves with assessing and managing the issues, risks, and tasks, communication, collaboration and knowledge sharing, document management, and disclosure activities, in addition to performing all of the product stewardship related to external requirements impacting an organization. The underlying activities or processes involve interpreting, tracking, and monitoring environmental regulations. All of this takes place in the context of evolving, strategic internal requirements. There are three primary categories of users - C\&R's legal data team; the customer organization's compliance function; and managers and engineers in the product research and development, manufacturing, and logistics functions. The core of the system is the CKMS repository, which is underpinned by a highly sophisticated data model. Figure 1 presents a conceptual model of such a CKMS, called Compliance-to-Product.

Institutional

Environment

\section{Compliance \& Risks Ltd. \\ Compliance-to-Product}

\section{IT Manufacturers}

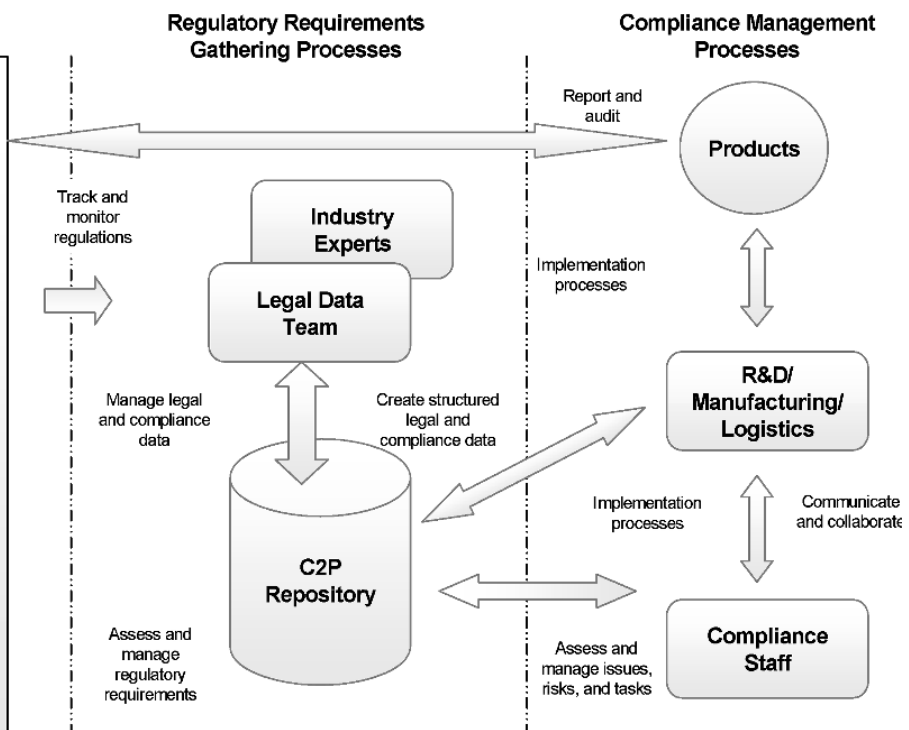

Figure 2. Compliance-to-Product Compliance-as-a-Service Conceptual Model 
In this model, external regulatory requirements gathering processes are conducted by $C \& R$, whose legal data team focuses on the jurisdiction, instrument type, and legal basis for compliance imperatives: as a result, their activities need to cover all of the business territories in which a company operates, in addition to juridico-political territories, future regional implementation areas, and so on. Identifying, managing, and tracking compliance imperatives is further complicated by the fact that they often fork into distinct regulatory requirements in "parent-child" configurations, in which the resulting child imperative may differ in terms of the criteria applied to business processes, behaviors, services, and products. Few, if any, organizations have the internal legal expertise to manage this complexity and to be able to track and monitor regulations, create and manage all legal and compliance data, while capturing the often subtle differences between, for example, an EU directive's local implementation in any of 27 member states, many of whom may "gold plate" legislation (i.e., make it more or less restrictive) to favor national industries or strengthen environmental protections.

Hence, in order to enable what are key processes in the model, C\&R put together its legal data team, which is comprised of lawyers in Ireland, the United Kingdom, and the United States. The legal data team also includes paralegals, engineers and environmental specialists. Its primary function, therefore, is to convert legislation from global regulatory institutions to create C2P's knowledge repository. Table 1 provides an example of the policy areas covered by the LDT and corresponding compliance imperatives by region as of 2007; these will be increased significantly by 2008 . Once the LDT has captured and properly formatted compliance imperatives, they are made available by $\mathrm{C} 2 \mathrm{P}$ to all organizational users who manage the organization's enterprise compliance processes. The application's features therefore enable users to readily assess and manage regulatory requirements and to manage product-related risks and issues. These processes are enhanced by communication and collaboration features that enable users to automate information sharing (e.g., by triggering risk alerts when legislation is modified or compliance imperatives are modified or introduced) and to support the firm's compliance implementation process.

\subsection{C\&R's Business Model}

The primary business model adopted by C\&R saw the establishment of its application and data hub in northeastern California. Locating the application hub in California was a strategic move, as several of its customers are Fortune 500 companies are located in Silicon Valley. The company's U.S. and European offices are linked to the hub using encrypted virtual private network (VPN) technology. Thus, development and legal staff at the company's headquarters, in addition to legal experts located worldwide, access the application using standard, secure web technologies. C\&R decided against hosting the client versions directly; instead, it outsourced the deployment of individually customized applications to a high profile application service provider in Sacramento, California, which implements a highly secure, industry-standard, service-oriented architecture. Figure 2 illustrates C\&R's business model.

Thus as with initial customers such as Napa Inc., each client site will have a secure VPN link to its particular customized version of C2P. The only data common to all application instances will be database entries related to compliance imperatives and related 
Table 1. Compliance-to-Product Knowledge Base of Global Product and Service Legislation

\begin{tabular}{|c|c|c|c|c|c|c|c|c|c|c|c|c|}
\hline $\begin{array}{c}\text { Regulatory } \\
\text { Region } \\
\text { Target }\end{array}$ & 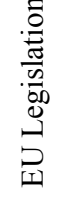 & 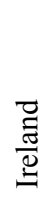 & 光 & $\begin{array}{l}\text { 出 } \\
\text { 足 }\end{array}$ & 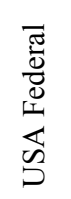 & 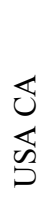 & $\begin{array}{l}Z \\
\text { Z } \\
\text { 岕 }\end{array}$ & 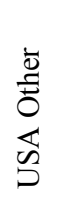 & 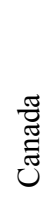 & 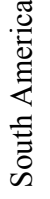 & 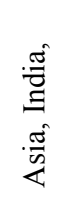 & 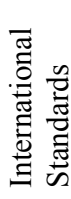 \\
\hline Batteries & 10 & & 3 & 2 & 5 & 2 & 1 & 15 & & 5 & 8 & 1 \\
\hline $\begin{array}{l}\text { Energy } \\
\text { efficiency }\end{array}$ & 22 & 1 & 4 & 6 & 48 & 6 & 1 & 12 & 2 & & 13 & 4 \\
\hline $\begin{array}{l}\text { Hazardous } \\
\text { substances }\end{array}$ & 69 & 3 & 19 & 66 & 41 & 30 & 4 & 64 & 5 & 9 & 38 & 23 \\
\hline Packaging & 34 & 3 & 10 & 71 & 1 & 1 & 1 & 22 & 1 & & 18 & 5 \\
\hline $\begin{array}{l}\text { Disposal, } \\
\text { take-back }\end{array}$ & 8 & & & 14 & 12 & 3 & 11 & 75 & 6 & 9 & 9 & 6 \\
\hline $\begin{array}{l}\text { Waste \& } \\
\text { waste mgmt.. }\end{array}$ & 23 & 5 & 7 & 81 & 2 & 6 & 1 & 7 & 6 & 1 & 9 & 8 \\
\hline $\begin{array}{l}\text { Public \& } \\
\text { green proc. }\end{array}$ & 10 & 5 & & & 5 & 1 & 2 & 1 & & & 2 & \\
\hline $\begin{array}{l}\text { EMC low } \\
\text { voltage }\end{array}$ & 21 & & & & & 1 & & & & & & \\
\hline ECO design & 43 & & 2 & & 7 & & & & & & 4 & 23 \\
\hline REACH & 32 & & 1 & & & & & & & & & \\
\hline $\begin{array}{l}\text { Money } \\
\text { laundering }\end{array}$ & 10 & & 12 & 5 & & & & 1 & & & & \\
\hline $\begin{array}{l}\text { Anti- } \\
\text { corruption }\end{array}$ & 8 & 1 & 10 & 22 & 3 & & & & & & & 2 \\
\hline $\begin{array}{l}\text { Health \& } \\
\text { safety }\end{array}$ & 16 & 16 & & 1 & 1 & 1 & & & & & 1 & 5 \\
\hline $\begin{array}{l}\text { Dual use, } \\
\text { export control }\end{array}$ & 19 & 4 & 24 & 23 & 12 & & & & & & 1 & 11 \\
\hline $\begin{array}{l}\text { Data } \\
\text { protection }\end{array}$ & 20 & 17 & 2 & 1 & 1 & & & & & & & 1 \\
\hline $\begin{array}{l}\text { Audit \& } \\
\text { governance }\end{array}$ & 12 & 15 & 12 & 1 & 1 & 1 & & & & & & 13 \\
\hline $\begin{array}{l}\text { Product } \\
\text { safety }\end{array}$ & 12 & 1 & & 4 & 2 & & & & & & & 9 \\
\hline $\begin{array}{l}\text { Marketing, } \\
\text { labeling }\end{array}$ & 7 & & & 8 & 3 & 2 & 1 & 2 & 4 & & 8 & 11 \\
\hline $\begin{array}{l}\text { Medical } \\
\text { regulation }\end{array}$ & 8 & & & & & & & & & & & \\
\hline $\begin{array}{l}\text { EU } \\
\text { procedures }\end{array}$ & 29 & & & & & & & & & & & \\
\hline Total sources & 413 & 71 & 106 & 307 & 144 & 54 & 22 & 199 & 24 & 24 & 111 & 122 \\
\hline
\end{tabular}




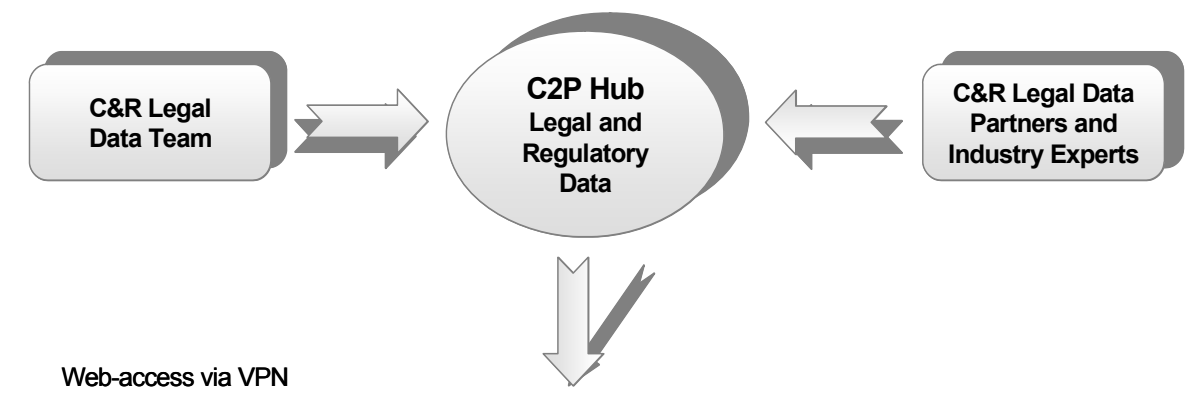

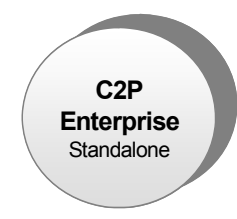

Stand-Alone or Integrated Solution at Client Site
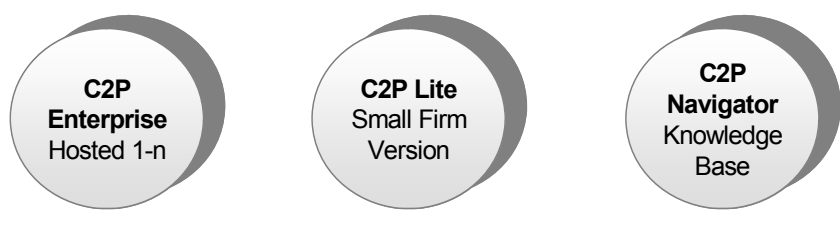

Hosted Compliance-as-a-Service Solutions

Web-access via VPN

Figure 2. Compliance-as-a-Service Business Model

data, documents, and so on, which emanate from the C2P hub. This partitioning ensures that confidential customer data is secured from access by other customers, or indeed employees of C\&R.

\section{APPLYING COMPLIANCE-AS-A-SERVICE CONCEPTUAL AND BUSINESS MODELS AT NAPA INC.}

The nub of the problem facing organizations in confronting environment-based institutional regulatory and corporate social responsibility pressures is that they generally do not have the necessary in-house legal capabilities to interpret, evaluate, capture, and store all relevant compliance-related information. These activities are usually out-tasked to legal experts who respond with voluminous reports that do little to lift the burden on compliance officers. Alternatively, in-house regulatory compliance requirements gathering demands strong legal competencies, as their focus must be on the geographic jurisdiction, instrument type, and legal basis for compliance imperatives. These were some of the challenges facing Napa Inc. prior to 2007.

Napa Inc. is a household brand name and a major player in the global IT industry worldwide. Due to the dearth of suitable environmental compliance management systems in the market in 2006, it piloted the use of C2P and subsequently adopted it as com- 
pliance-as-a-service using the aforementioned business model. According to Napa's Environment Department, the company's major challenge in dealing with institutional pressures in its organizational field (in that it sources components from the broader electrical and electronic sectors) and population (e.g., the high-tech sector) is that

\begin{abstract}
policy imperatives are exponentially growing, in the environmental arena the policy is focusing increasingly on product issues (RoHS, Power management, labeling, packaging design) and has been steadily moving away from end-ofpipe policy typical of the 1980s and 1990s [Environmental Health and Safety] regulations. Added to this, unlike other policy areas, environmental policy is enforced at multiple levels adding regional, national and local level data points (e.g., battery marking and recycling is enforced by European Commission, UK DEFRA and DTI, UK Regional Environment Agencies, local authorities, city councils).
\end{abstract}

Product recall and exclusion from particular markets were cited by Napa's managers as being some of the ongoing threats to the company in the face of such regulations. Napa argues that it, and its competitors, must address several issues in order to deal with this challenge: The first is how to avoid compliance officers and R\&D manufacturing engineers spending 100 percent of their resources on tracking policy, associated standards, and regulatory measures, as opposed to maintaining delivery of higher value-added activities such as compliance assessments, addressing and managing issues, and implementing compliance with imperatives. The second issue concerns how to tie the actions and decisions taken at a product team level with the requirements, terms, definitions, and guidance provided by legislators. The third issue concerns the problem of how to reduce time and cost associated with getting independent guidance and assessment on regulatory definitions and requirements.

\title{
5.1 Napa's Experiences with Compliance-as-a-Service
}

Prior to its adoption of C2P, Napa adopted a five-stage process in order to help it manage compliance viz. (1) track and monitor all relevant regulations in the global marketplace; (2) assess all related risks in terms of process and product; (3) raise awareness across the organization, especially in engineering, design, $\mathrm{R} \& \mathrm{D}$, and manufacturing, and enhance intra-organizational communications across all relevant functions; (4) implement compliance solutions in engineering and design functions at the earliest possible opportunity; (5) review the effectiveness of the steps taken and the level of compliance achieved. These steps were increasingly proving to be difficult to manage in terms of the scope and complexity of the global regulatory environments in which Napa operates. Like many other organizations, Napa was managing compliance using information gleaned from legal advisors and mapping this onto products, subcomponents, and so on, using Excel spreadsheets. Table 2 illustrates the support that $\mathrm{C} 2 \mathrm{P}$ offers to Napa's compliance processes.

Regulatory Requirements Gathering Process: As indicated, C2P's regulatory requirements process is conducted by $C \& R$ 's legal data team, with input from industry partners (such as law firms, consultants, policy area experts), and other sources. The 
Table 2. Napa's Five-Stage C2P-Enabled Compliance Process

\begin{tabular}{|ll|l|}
\hline \multicolumn{2}{|c|}{ Napa Inc. Compliance Activities } & \multicolumn{1}{c|}{ Supporting C2P Features and Functions } \\
\hline 1. & Track and monitor & $\begin{array}{l}\text { Structured, dynamic database of compliance } \\
\text { imperatives }\end{array}$ \\
\hline 2. & Assess risk & $\begin{array}{l}\text { Detailed regulatory requirements, impact, issues, } \\
\text { unambiguous terms and definitions, risk ratings }\end{array}$ \\
\hline 3. & Raise awareness and communication & Alerts, comments, watches, and shared searches \\
\hline 4. & Implement compliance solutions & $\begin{array}{l}\text { Internal specifications, action plans, assignment } \\
\text { and reports }\end{array}$ \\
\hline $5 . \quad$ Review 1-4 & $\begin{array}{l}\text { Historical reports, compliance indicators, and } \\
\text { management summaries }\end{array}$ \\
\hline
\end{tabular}

scope of this process is that it encapsulates all of the business territories in which Napa operates, in addition to all juridico-political territories, future regional implementation areas, and so on. The complexity of capturing these types of data stands in stark contrast to the type of support provided by the majority of extant ECMS (e.g., SAP's compliance for product), where users create static "lists" of compliance requirements, rather than the multidimensional data structures needed to model compliance imperatives and requirements, and which also need to be updated in real-time. C2P, therefore, captures global regulatory imperatives, and represents them not as one-dimensional lists, but in complex data structures that Napa's compliance officers and other users can easily navigate and map onto internal specifications (in $\mathrm{C} 2 \mathrm{P}$ format), products, subassemblies, parts, materials, and substances. Feedback from Napa's compliance and R\&D teams indicated that $\mathrm{C} 2 \mathrm{P}$ "adds value" to the company's compliance management processes, as the compliance-as-a-service application ensures that "source regulatory data is delivered preformatted, structured, and ready to use out of the box" (Compliance Officer, Napa Inc.). $\mathrm{C} 2 \mathrm{P}$ was also argued to provide "a universal panoramic view of all relevant impacts to product or company operations" and it "gives instant, live snapshots on policy areas that are not adequately covered or understood- $[\mathrm{C} 2 \mathrm{P}]$ helps guide management to allocate resources to appropriate risk areas."

Compliance Management Process: Napa's compliance officers and other users have full visibility into the status of its compliance activities using a simple dashboard and complex searching and reporting functionality. In most scenarios, manufacturing organizations will set down product specifications, including materials to be used in subcomponents at the R\&D or product design stage. An important feature of C2P is its ability to allow Napa to view the impact of regulations on, and issues around, products, subassemblies, parts, materials, and substances in real time. This means that once a regulatory requirement changes, or a new one emerges, or new data is fed into the system, the status of all related products can change, down to constituent materials, and on to parts provided by suppliers, communicated to "responsible" users using dashboard and email alerts. C2P's analysis features help users analyze compliance imperatives and requirements impacts on products, subassemblies, parts, materials, and substances. This feature encompasses facilities to map supplier data against compliance requirements so as to identify noncompliant parts, materials, or substances. As with other ECMSs, C2P features a personal dashboard, which supports access to the following features: 
- An issue management feature helps Napa's compliance professionals, product design engineers, and others collaboratively evaluate, escalate, and address product and material compliance issues.

- A risk ratings feature displays a product's risk status for each compliance issue.

- The ability to allow Napa's compliance officer to delegate and monitor issues and responsibilities to relevant staff.

- An action plan feature, so that users can associate milestones with, and manage tasks for, each issue.

- An exception or alarm feature to remind users, and help them track the status, of assigned areas of responsibility.

- The ability to create custom reports according to their issues and products.

- The ability to have multiple views so that users can navigate between summary views and more detailed information.

Knowledge Management Process: Napa's user community felt that one of the strong features of the $\mathrm{C} 2 \mathrm{P}$ was its knowledge-sharing capabilities and tools. The purpose of these features is to provide an additional dimension to enhance the understanding of users to enhance compliance-related decision making. Several of these features are accessible from C2P's dashboard, including

- $\quad$ Capturing discussion threads in instant messages and e-mail threads between users on any topic.

- Create contexts (i.e., background information) for classifying and reporting the evolving impact of compliance issues on products.

- Capturing a history of all changes to regulatory imperatives and requirements and associated changes to products, subassemblies, parts, materials, and substances.

- Automatic e-mail and/or instant messaging notification of any changes in the regulatory status of products, subassemblies, parts, materials, and substances.

- An attachment feature to provide links to, or to attach directly, related documents (e.g., legal interpretations or advice, industry journal articles, reports, etc.) that describe in-depth compliance imperatives, requirements, issues, impacts, or data on products, subassemblies, parts, materials, and substances.

- Search features to allow users to run queries and produce reports based on specific parameters.

Napa's compliance executive summed up comments from colleagues by stating that " $\mathrm{C} 2 \mathrm{P}$ has shown us that the era of paying external organizations to dump information on our doorstep has come to an end." He maintained that the application "enables our compliance team to move away from the inordinate amount of time spent on tracking and monitoring activities and to focus on activities 2, 3, and 4 [see Table 2] which are the bits that really add value to the company." Another member of the Napa's compliance team supported this and stated that " $\mathrm{C} 2 \mathrm{P}$ helps us to a specific risk assessment for all affected products, getting quickly to impacts and risks." Thus, the C2P application offers faster time to knowledge to Napa in managing product compliance and minimizing any risk to the company by being out of compliance. 


\section{SUMMARY AND CONCLUSIONS}

This paper describes the changing institutional environment confronting high-tech manufacturing organizations in the IT sector. Growing societal concerns with the planet's environment has led governments and their agencies across the globe to institute highly complex and far-reaching legislation that has significant implications for all IT products, their production, use, and disposal. Thus, there is no place to hide for IT manufacturers, wherever they are based. This development has brought an important and new challenge to organizations to respond to such institutional pressures by instituting new compliance-oriented organizational protocols and procedures. As the problems facing organizations in achieving compliance with environment-oriented regulatory requirements are essentially information-based, then it is no surprise to find that a new breed of IS has emerged-environmental compliance management systems. While several such solutions are currently available in the marketplace, they have not been the focus of information systems research or industry analysis. This study's major contribution is that it identified a ground-breaking approach to solving the problem of organizational responses to increasing institutional and stakeholder pressures (often climate change related) through the provision of compliance-as-a-service by a small, innovative software company-Compliance and Risks Ltd.

The paper revealed that compliance-as-a-service emerged as a viable value proposition to organizations as it addresses: (1) the complexity of the global institutional regulatory environments in which they operate, and (2) the inability of such companies to form adequate responses to those challenges due to the dearth of in-house legal capabilities, and the resources required to provide adequate IT support for the application of new protocols and procedures. It is clear from marketplace assessments made by the authors of this study, and confirmed by practitioners in Napa Inc., and other Fortune 500 and 100 organizations, that, with few exceptions, both the organizations themselves and extant software vendors are not meeting the compliance and risks needs of the IT manufacturing and related sectors. This study illustrated how one innovative software company identified these requirements and responded by building an IT artefact that was tailored to help organizations institute appropriate protocols and procedures to meet the regulatory compliance needs of these sectors. The key differentiator of C\&R's C2P application, and one that conveys a comparative advantage on it over other vendor offerings, is that it approaches the problem from a legal/compliance perspective and offers a combination of software, regulatory data, and data services. Alternative approaches from competing vendors are based on document management, supply chain management, or enterprise resource planning perspectives, none of which captures the multidimensional nature of regulatory compliance imperatives and their impact down the product hierarchy to component materials. This lacuna prevents adopting organizations using such ECMS for developing effective protocols and applying related procedures to address institutional challenges. It must also be noted that while the knowledge and skills of C\&R's legal data team are important, so too is the conceptual model underpinning the $\mathrm{C} 2 \mathrm{P}$ application in that that captures the legal essence of the institutional influences, and thereby enables the team to translate the complex regulations into basic compliance imperatives such that users can understand them. In conclusion, the practical success of 
the C2P application with a growing number of Fortune 100 and 500 companies provides support for its underlying concept and architecture in delivering compliance-as-a-service and underpins its position as an innovative solution in this emergent area of the IS field.

\section{References}

Avila, G. 2006. "Product Development for RoHS and WEEE Compliance," Printed Circuit Design and Manufacture (23:5), pp. 28-31.

Baskerville, R. L. 1999. "Investigating Information Systems with Action Research," Communications of the Association for Information Systems (2:19), October.

Brodkin, J. 2007. "Hosted Software Manages Environmental Compliance," Network World, August 1 (http://www.networkworld.com/news/2007/080107-hosted- software.html).

Brown, J. 2006. "The Product Compliance Benchmark Report: Protecting the Environment, Protecting Profits," Aberdeen Group, Boston, September.

Bush, S. 2007. "EU's REACH Directive Will Hit Electronics Firms," Electronics Weely.com February 28 (http://www.electronicsweekly.com/articles/2007/02/28/ 40856).

Chiasson, M., and Davidson, L. 2005. "Taking Industry Seriously in Information Systems Research," MIS Quarterly (29:4), pp. 591-605.

Dell. 2007. "Values in Action: Dell Sustainability Report, Fiscal Year 2007 in Review," Dell Inc. (http://www.dell.com/downloads/global/corporate/environ/report07.pdf).

DiMaggio, P. J., and Powell, W. W. 1983. "The Iron Cage Revisited: Institutional Isomorphism and Collective Rationality in Organizational Fields," American Sociological Review (48:2), pp. $147-160$.

Eisner, M. A. 2004. "Corporate Environmentalism, Regulatory Reform, and Industry SelfRegulation: Toward Genuine Regulatory Reninvention in the United States," Governance: An International Journal of Policy, Administrations and Institutions (17:2), pp. 145-167.

European Commission. 2006. "REACH in Brief," Enterprise \& Industry, December 12 (http://ec.europa.eu/enterprise/reach/overview_en.htm).

Goosey, M. 2007. "Implementation of the RoHS Directive and Compliance Implications for the PCB Sector," Circuit Design (33:1), pp. 47-50.

Greenemeier, L. 2007. "Greenpeace: Apple iPhone More Brown than Green," Scientific American.com News, October 18 (http://www.sciam.com/article.cfm?id=iphone-morebrown-than-green).

Hewlett Packard. 2006. "HP FY06 Global Citizenship Report.” March 17 (www.hp.com/hpinfo/ globalcitizenship/gcreport/index.html).

Hristev, I. 2006. "Rohs and WEEE in the EU and US," European Environmental Law Review, March, oo. 62-74.

Hutter, B. 1997. Compliance, Regulation and Environment, Oxford, UK: Clarendon Press.

Kellow, A. 2002. "Steering through Complexity: EU Environmental Regulation in the International Context," Political Studies (50:1), pp. 43-60.

McLean, C., and Rasmussen, M. 2007. "The Forrester Wave ${ }^{\mathrm{TM}}$ : Enterprise Governance, Risk, and Compliance Platforms, Q4 2007," Forrester, December 21 (http://www.forrester.com/ Research/Document/Excerpt/0,7211,41751,00.html).

Murugesan, S. 2007. "Going Green with IT: Your Responsibility Toward Environmental Sustainability," Cutter Consortium Business-IT Strategies Executive Report (10:8), August (http://www.cutter.com/alignment/fulltext/reports/2007/08/index.html)

North, D. C. 1991. "Institutions," Journal of Economic Perspective (5:1), Winter, pp. 97-112.

Pecht, P. 2004. "The Impact of Lead-Free Legislation Exemptions on the Electronics Industry," IEEE Transactions on Electronics Packaging Manufacturing (27:4), pp. 221-232. 
Powell, W. W. 1991. "Expanding the Scope of Institutional Analysis," in The New Institutionalism in Organizational Analysis, W. W. Powell and P. J. DiMaggio (eds.), Chicago: University of Chicago Press, pp. 183-203.

Scott, W. R. 2001. Institutions and Organizations, Thousand Oaks, CA: Sage Publications,.

Scott, W. R. 2004. "Institutional Theory," in Encyclopedia of Social Theory, G. Ritzer (ed.), Thousand Oaks, CA: Sage Publications, pp. 408-414.

Spiegel, R. 2005. "Cost of Compliance - 2 to 3 Percent of Cost of Goods," Design News, September 6 (http://www.designnews.com).

Stake, R. E. 1995. The Art of Case Study Research, Thousand Oaks, CA: Sage Publications.

Taylor, C. 2005. "The Evolution of Compliance," Journal of Investment Compliance (64), pp. 54-58.

Yin, R. K. 2003. Case Study Research: Design and Method, Thousand Oaks, CA: Sage Publications Inc.

\section{About the Authors}

Tom Butler is a Senior Lecturer in Business Information Systems, University College Cork, Ireland. A former IT professional, he worked for 27 years in the telecommunications sector. Tom's research focuses on investigating the origins of firm-level IT capabilities and the design, development, and implementation of information systems, particularly knowledge management systems (KMS). From 2003-2006, he was lead researcher and project manager on two major action research-based initiatives on the design, development, and deployment of IT-enabled KMS from the United Nations Population Fund Agency and the Irish government. Since 2005, Tom has been conducting research into the design of compliance knowledge management systems (CKMS). His work has been published outlets including Information Systems Journal, Journal of Strategic Information Systems, Journal of Information Technology, and the proceedings of major international conferences such as the International Conference on Information Systems, the European Conference on Information Systems, and IFIP Working Groups 8.2 and 8.6. Tom can be reached atTButler@afis.ucc.ie.

William Emerson is a College Lecturer in Business Information Systems at University College Cork. A former IT professional, he worked for 15 years in financial services organizations as an analyst programmer and system architect. His current research interests focus on the design, implementation, and use of compliance knowledge management systems, particularly in the financial services sector. Bill's research has been published in journals, including Journal of Strategic Information Systems, and in the proceedings of conferences such as the European Conference on Information Systems. Bill can be reached at b.emerson@ucc.ie.

Damien McGovern is founder and CEO of Compliance \& Risks Ltd. Damien is a lawyer and spent a considerable portion of his career working for Deloitte \& Touche in Europe. It was in this capacity that he identified the need for a dedicated compliance knowledge management system (CKMS). Consequently, he began to draft a blueprint for his Compliance-to-Product application in 2001. His CKMS concept has been tested and validated by Compliance \& Risks' clients and is now fully operational in several sites. C\&R has its headquarters in Cork, Ireland, while its software development team is located in northern California and in Ireland. Damien's team of governance, risks, and compliance domain experts include lawyers in Ireland, the United Kingdom, Europe, and the United States. Damien can be reached at d.mcgovern@ complianceandrisks.com. 